\title{
DISTANCE BETWEEN MITRAL ANULUS AND PAPILLARY MUSCLES: ANATOMIC STUDY IN NORMAL HUMAN HEARTS
}

Tetsuro Sakai, MD

Yutaka Okita, MD, $\mathrm{PhD}^{\mathrm{b}}$

Yuichi Ueda, $\mathrm{MD}, \mathrm{PhD}^{\mathrm{c}}$

Takafumi Tahata, $\mathrm{MD}^{\mathrm{d}}$

Hitoshi Ogino, MD, $\mathrm{PhD}^{\mathrm{a}}$

Katsuhiko Matsuyama, MD, $\mathrm{PhD}^{\mathrm{a}}$

Shigehito Miki, MD
Background: Preservation of the annulo-papillary muscle continuity in mitral valve replacement is important. Even in patients who require excision of the mitral apparatus, the continuity can be restored. However, there is no guide to the proper length for the resuspension. Methods: In 57 normal cadaveric hearts, the distance from the tip of the papillary muscle to its corresponding mitral anulus was directly measured. Results: The distance from the tip of the anterolateral papillary muscle to the left trigone (10-o'clock position: D10) and to the point between the anterior and the middle scallops of the mural leaflet (8o'clock position: D8) was $23.5 \pm 3.7 \mathrm{~mm}$ and $23.2 \pm 3.6 \mathrm{~mm}$, respectively. The distance from the tip of the posteromedial papillary muscle to the right trigone (2-o'clock position: D2) and to the point between the middle and the posterior scallops of the mural leaflet (4-o'clock position: D4) was $23.5 \pm 4.0 \mathrm{~mm}$ and $23.5 \pm 3.9 \mathrm{~mm}$, respectively. There was no statistically significant difference among the 4 distances $(P=.96)$. Each distance was significantly longer than the corresponding chordae tendineae (D10 vs the anterior main chorda: $17.2 \pm 3.9 \mathrm{~mm}$, D8 vs the anterior cleft chorda: $14.5 \pm 3.2 \mathrm{~mm}$, D2 vs the posterior main chorda: $17.9 \pm 4.3 \mathrm{~mm}$, and D4 vs the posterior cleft chorda: $14.9 \pm 3.2 \mathrm{~mm}$, respectively; $P=.0001)$. The mean distance had a significant correlation with the mitral annular diameter $(r=0.31, P=.019)$. Conclusions: In normal hearts, the annulo-papillary muscle distances of the mitral apparatus are similar in 2-, 4-, 8-, and 10-o'clock positions and correlate with the mitral annular diameter. (J Thorac Cardiovasc Surg 1999;118:636-41)
$T^{1}$ he importance of the continuity between the mitral anulus and the papillary muscle for left ventricular performance $^{1-5}$ and for prevention from postoperative mid-ventricular rupture ${ }^{6,7}$ in mitral valve replacement has been widely recognized. In case of mitral valve replacement for patients who require total excision of the leaflets and the chordae tendineae, mitral allograft $^{8}$ or expanded polytetrafluoroethylene (ePTFE) sutures $^{9,10}$ have been used to restore the annulo-papil-

From the Department of Cardiovascular Surgery, Tenri Hospital, Nara, ${ }^{a}$ Department of Cardiovascular Surgery, National Cardiovascular Center, Osaka, ${ }^{\mathrm{b}}$ Department of Thoracic Surgery, Nagoya University, Nagoya, ${ }^{\mathrm{c}}$ and Department of Cardiovascular Surgery, Kishiwada City Hospital, Osaka, ${ }^{\mathrm{d}}$ Japan.

Received for publication Oct 27, 1998; revisions requested Jan 27, 1999; revisions received June 3, 1999; accepted for publication July 19, 1999.

Address for reprints: Tetsuro Sakai, MD, Division of Cardiovascular Surgery, The Toronto Hospital, 13 EN-222, Toronto, Ontario, Canada M5G 2C4 (E-mail: tedsakai@hotmail.com).

Copyright (C) 1999 by Mosby, Inc.

$0022-5223 / 99 \$ 8.00+0 \quad \mathbf{1 2 / 1 / 1 0 1 5 6 0}$ lary muscle continuity. The proper length of the ePTFE sutures or allograft chordae for the resuspension, however, is difficult to determine. We describe an anatomic study of the distance between the mitral anulus and papillary muscles in 57 normal hearts for a guide to the resuspension procedure in mitral valve replacement.

\section{Materials and methods}

Fifty-seven consecutive human hearts were studied at autopsy. All of the subjects were Japanese aged 23 to 95 years (67.5 \pm 11.3 years, mean \pm standard deviation). The subjects included 38 men and 19 women. Body weights ranged from 24 to $75 \mathrm{~kg}(45.4 \pm 10.9 \mathrm{~kg})$ and the heights of the bodies ranged from 136 to $179 \mathrm{~cm}(158.1 \pm 7.8 \mathrm{~cm})$. Hearts with any evidence of valvular disease or ischemic heart disease were excluded from this study. The nomenclature of the mitral valve system was based on the report of Lam and associates ${ }^{11}$ (Fig 1).

Immediately after the heart was taken from the body, the left atrium was excised to allow full visualization of the mitral valve. Without any ventriculotomy, the heart was placed on a wet gauze sheet loosely covering a well so that the heart was 


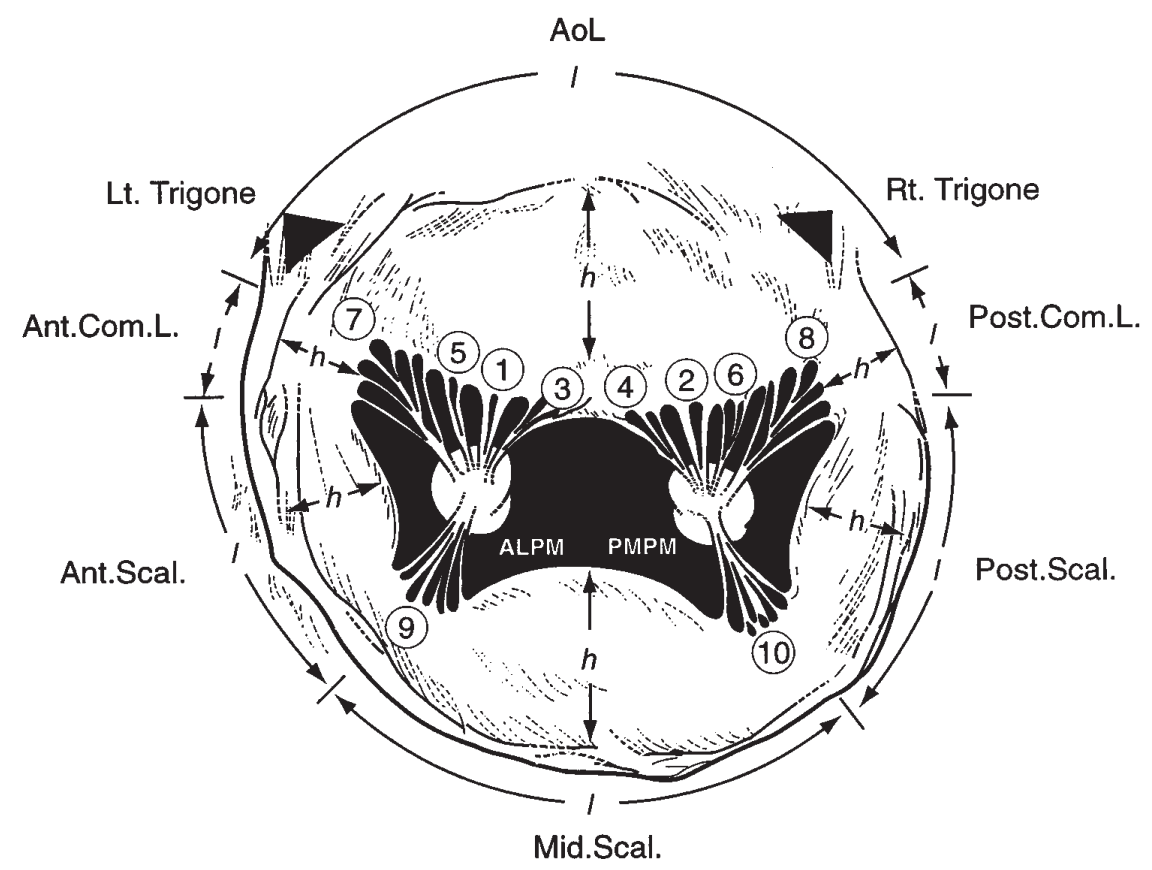

Fig 1. Mitral apparatus. $A L P M$, Anterolateral papillary muscle; $P M P M$, posteromedial papillary muscle; $A o L$, aortic leaflet; Ant.Com.L., anterior commissural leaflet; Post.Com.L., posterior commissural leaflet; Ant.Scal., anterior scallop; Mid.Scal., middle scallop; $h$, height of a leaflet; $l$, length of the attachment of a leaflet; Post.Scal., posterior scallop; Rt. Trigone, right fibrous trigone; Lt. Trigone, left fibrous trigone; 1, anterior main chorda; 2, posterior main chorda; 3 , anterior paramedial chorda; 4 , posterior paramedial chorda; 5 , anterior paracommissural chorda; 6, posterior paracommissural chorda; 7, anterior commissural chorda; 8 , posterior commissural chorda; 9 , anterior cleft chorda; 10 , posterior cleft chorda.

situated in the "gauze cradle" without any distortion of its shape. With gentle upward tension on the leaflets to straighten the chordae tendineae, the annulo-papillary muscle distances were measured with a caliper (with a metric rule graduated to $1 \mathrm{~mm}$ ) in 4 directions according to our resuspension method. ${ }^{12}$ The 2 distances were measured from the tip of the anterolateral papillary muscle to the anulus: to the left fibrous trigone (10-o'clock position) and to the point between the anterior and the middle scallops of the mural leaflet (8o'clock position). Also, the 2 distances were measured from the tip of the posteromedial papillary muscle to the anulus: to the right fibrous trigone (2-o'clock position) and to the point between the middle and the posterior scallops of the mural leaflet (4-o'clock position) (Fig 2). We defined the "tip" of the papillary muscle as the point of insertion of the main chordae. Even in the hearts with a papillary muscle with multiple heads, ${ }^{13}$ the insertion of the main chordae at the papillary muscle was successfully located in this study. Then the left ventricle was incised along the lateral border to avoid damaging the papillary muscles. The mitral valve was cut through between the posterior commissural leaflet and the posterior scallop of the mural leaflet. The width and height of the leaflets and the length of the chordae tendineae were measured with a caliper. The mitral annular circumference was calculated with the sum of the all attachments of the valves. Then it was divided by $\pi$ to yield the mitral annular diameter. All measurements were accomplished before fixation of the hearts with $37 \%$ formaldehyde solution.

Data were analyzed with SPSS software package for Windows version 8.0 (SPSS Inc, Chicago, Ill). All results are shown as mean \pm standard deviation. Comparisons of continuous variables in 4 annulo-papillary distances were performed by a 1-way analysis of variance, and significant differences were specified by Duncan's multiple range test. Each annulo-papillary distance and the length of the corresponding chorda was compared by paired $t$ test. Pearson's correlation coefficients and simple regression were used to analyze the relationship between the mean distance and the mitral annular diameter, body surface area, and heart weight.

\section{Results}

Fig 3 illustrates the 4 annulo-papillary muscle distances and their corresponding chordae tendineae. The annulo-papillary muscle distances were similar in all 4 positions ( $P=.96$, by 1 -way analysis of variance). Each distance was significantly longer than the length of the corresponding chordae tendineae: the distance 


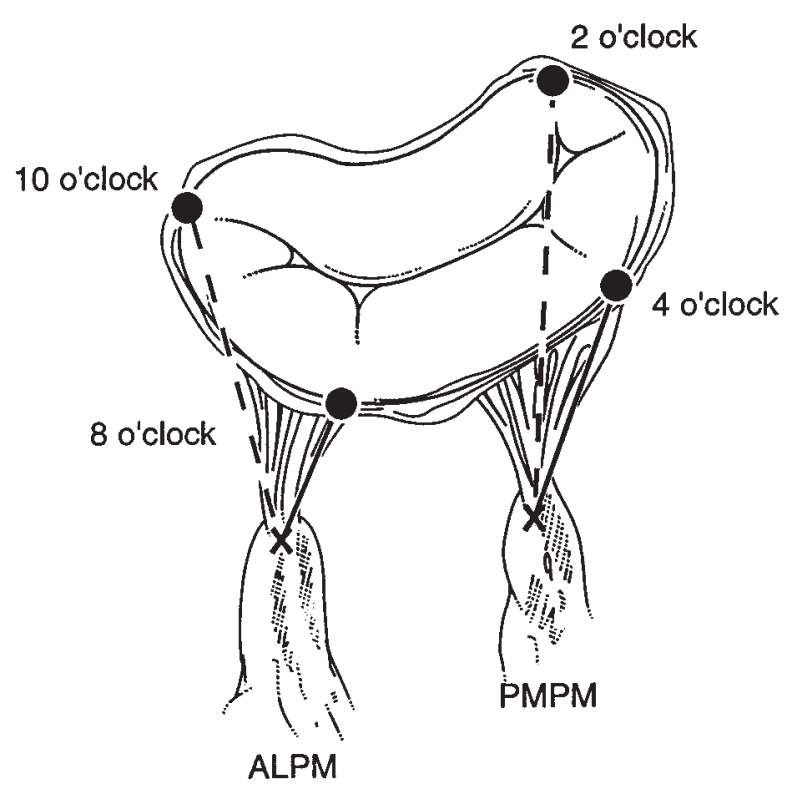

Fig 2. Diagram of the annulo-papillary muscle distances that were measured in the study: 2-o'clock position, The anulus at the right fibrous trigone; 4 -o' clock position, the anulus at the point between the middle and the posterior scallops of the mural leaflet; 8-o'clock position, the anulus at the point between the anterior and the middle scallops of the mural leaflet; 10-o'clock position, the anulus at the left fibrous trigone; $A L P M$, anterolateral papillary muscle; $P M P M$, posteromedial papillary muscle.

from the anterolateral papillary muscle to the 10o'clock position versus the anterior main chorda $(23.5$ $\pm 3.7 \mathrm{~mm}$ vs $17.2 \pm 4.1 \mathrm{~mm}$ ), the distance from the anterolateral papillary muscle to the 8 -o'clock position versus the anterior cleft chorda $(23.2 \pm 3.6 \mathrm{~mm}$ vs 14.5 $\pm 3.2 \mathrm{~mm}$ ), the distance from the posteromedial papillary muscle to the 2-o'clock position versus the posterior main chorda $(23.5 \pm 4.0 \mathrm{~mm}$ vs $17.8 \pm 4.7 \mathrm{~mm})$, and the distance from the posteromedial papillary muscle to the 4-o'clock position versus the posterior cleft chorda $(23.5 \pm 3.9 \mathrm{~mm}$ vs $14.8 \pm 3.1 \mathrm{~mm})($ all, $P=$ .0001).

The mitral annular diameter ranged from 22.3 to 40.1 $\mathrm{mm}(29.7 \pm 3.5 \mathrm{~mm})$. The heart weight ranged from 150 to $490 \mathrm{~g}(307.5 \pm 68.6 \mathrm{~g})$. Body surface area ranged from 1.03 to $1.73 \mathrm{~m}^{2}\left(1.38 \pm 0.17 \mathrm{~m}^{2}\right)$. There were weak but statistically significant correlations between the mean annulo-papillary muscle distances $(23.5 \pm 3.1 \mathrm{~mm})$ and the mitral annular diameters $(r=$ $.31, P=.019)$ (Fig 4), the heart weights $(r=.36, P=$ $.006)$, and the body surface areas $(r=.31, P=.018)$.

The other measurements of the mitral apparatus are described in Table I.

\section{Discussion}

The importance of annulo-papillary muscle continuity for global left ventricular function in prosthetic valve replacement for mitral regurgitation has been widely recognized. ${ }^{1-5}$ We have applied the concept of restoration of annulo-papillary muscle continuity in patients with mitral stenosis since 1984. Our clinical result showed that postoperative regional shortenings of the left ventricle were greater in patients who underwent chordal preserving mitral valve replacement than in patients with the conventional chordal severing procedure. ${ }^{12}$ Although some controversy exists whether this method offers significant postoperative functional improvement for the patients with mitral stenosis, the preservation of the annulo-papillary continuity is still important to prevent transverse mid-ventricular disruption after mitral valve replacement. ${ }^{6,7}$ Even in patients with severe mitral stenosis who require resection of the whole valve leaflets and chordae tendineae, it is possible to restore the continuity by resuspending the papillary muscle to the mitral anulus either with mitral allograft $^{8}$ or ePTFE sutures. ${ }^{9}$

One of the technical problems in restoration of annulo-papillary continuity with ePTFE sutures is how to determine the proper suture length. Although Frater ${ }^{14}$ described the anatomic rules of determining the length of the artificial chordae in the case of chordal replacement for mitral regurgitation, there could be no chordae tendineae available to assess the proper length of ePTFE sutures in severe mitral stenosis. The resuspension length of the papillary muscle is important. If it is too short, excessive tension might cause diastolic dysfunction or tissue disruption at the site of the ePTFE sutures. ${ }^{15}$ If too long, the ePTFE sutures cannot transmit enough tension during a cardiac cycle. To the best of our knowledge, none of the reports has described a proper method to determine the resuspension length.

We performed the present study to provide an anatomic reference for the resuspension procedure. We measured the papillary muscle resuspension length in normal cadaveric hearts instead of the hearts with mitral stenosis because of the lack of specimens. Before mitral valve operations, annulo-papillary muscle distance in patients with mitral stenosis might be shorter than that in the normal population. Gash and coworkers ${ }^{16}$ demonstrated reduced left ventricular enddiastolic volume index of patients with mitral stenosis compared with control subjects. We, however, think the annulo-papillary muscle distance measured in the normal hearts could be applicable for the heart with mitral stenosis at the time of mitral valve surgery, because left ventricular end-diastolic volume generally increases 


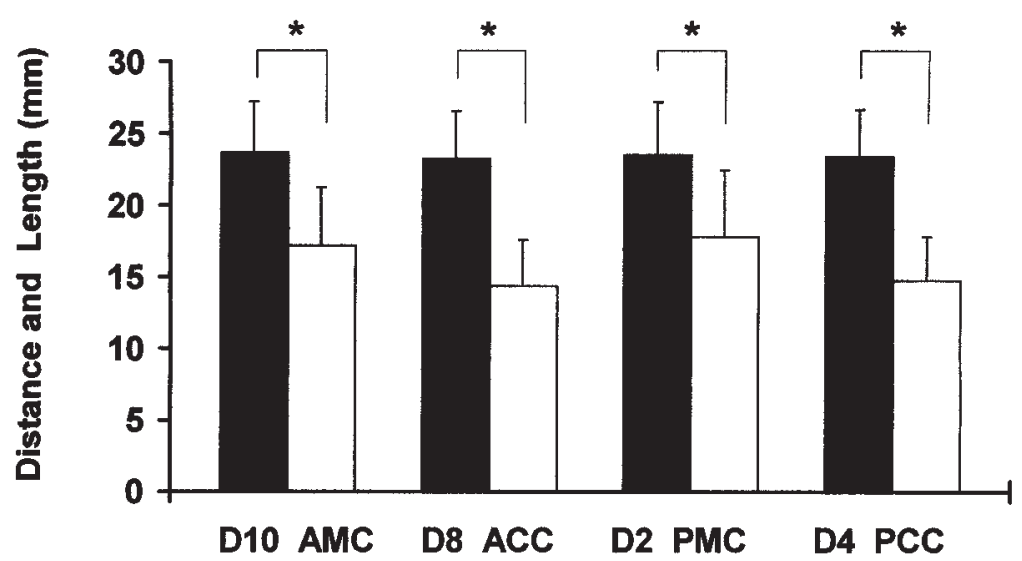

Fig 3. Annulo-papillary muscle distance and the length of the corresponding chordae tendineae. D10, The distance from the tip of the anterolateral papillary muscle to the anulus at the left fibrous trigone; $A M C$, anterior main chorda; $D 8$, the distance from the tip of the anterolateral papillary muscle to the anulus between the anterior and the middle scallops of the mural leaflet; $A C C$, anterior cleft chorda; $D 2$, the distance from the tip of the posteromedial papillary muscle to the anulus at the right fibrous trigone; $P M C$, posterior main chorda; $D 4$, the distance from the tip of the posteromedial papillary muscle to the anulus between the middle and the posterior scallops of the mural leaflet; $P C C$, posterior cleft chorda. $* P=.0001$ by paired $t$ test. There was no statistical difference among the 4 distances $(P=.96$ by analysis of variance $)$.

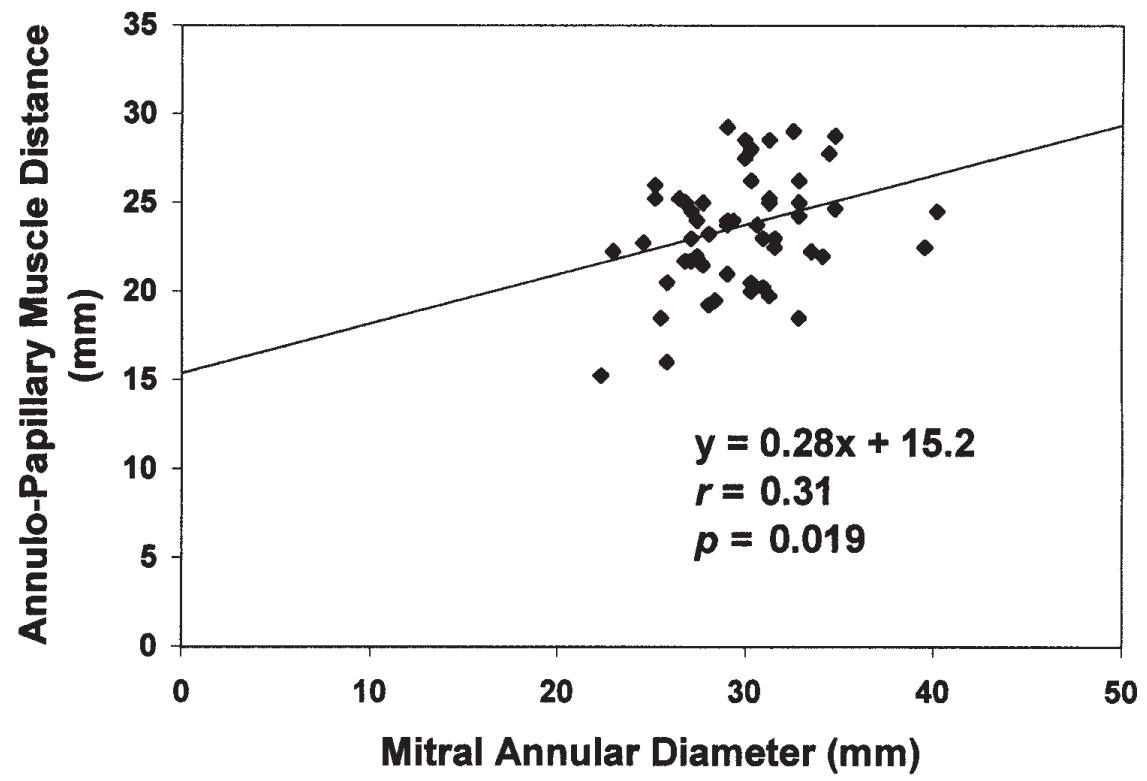

Fig 4. Distribution of the mean annulo-papillary muscle distances relative to the mitral annular diameters.

after successful percutaneous mitral valvuloplasty ${ }^{17}$ in which the native annulo-papillary muscle continuity has been preserved. The relevance of cadaveric heart to an arrested continuously perfused heart was not clear. However, Komeda and associates ${ }^{18}$ showed that the distance from the tip of the papillary muscle to the mitral annular plane was constant, regardless of cardiac cycle and loading conditions. Therefore we believe the use of the cadaveric hearts for the measurement is valid.

Acar and associates ${ }^{8}$ directly measured the distance from the plane of the mitral anulus to the tip of the anterolateral papillary muscle (D1) and from that to the tip of the posteromedial papillary muscle (D2) in 82 human mitral allografts. They measured perpendicular 
Table I. Measurements of mitral apparatus in normal hearts

\begin{tabular}{|c|c|c|}
\hline & Present study & Carpentier $^{20}$ \\
\hline Weight of the heart (g) & $307.5 \pm 68.6$ & 340 \\
\hline Circumference (mm) & $93.2 \pm 11.0$ & $116 \pm 3.5$ \\
\hline \multicolumn{3}{|l|}{ Aortic leaflet } \\
\hline Attachment (mm) & $32.0 \pm 4.8$ & $32 \pm 1.3$ \\
\hline Height (mm) & $23.4 \pm 2.9$ & $23 \pm 0.9$ \\
\hline \multicolumn{3}{|l|}{ Main chordae } \\
\hline Anterior (mm) & $17.2 \pm 3.9$ & $19 \pm 0.4$ \\
\hline Posterior (mm) & $17.9 \pm 4.3$ & $17 \pm 0.2$ \\
\hline \multicolumn{3}{|l|}{ Paramedial chordae } \\
\hline Anterior (mm) & $16.2 \pm 3.7$ & $15 \pm 0.5$ \\
\hline Posterior (mm) & $16.8 \pm 3.4$ & NA \\
\hline \multicolumn{3}{|l|}{ Paracommissural chordae } \\
\hline Anterior (mm) & $15.5 \pm 3.0$ & $17 \pm 0.3$ \\
\hline Posterior (mm) & $17.5 \pm 4.0$ & NA \\
\hline \multicolumn{3}{|l|}{ Mural leaflet } \\
\hline \multicolumn{3}{|l|}{ Anterior scallop } \\
\hline Attachment (mm) & $14.1 \pm 3.6$ & NA \\
\hline Height (mm) & $11.2 \pm 2.3$ & $9 \pm 1$ \\
\hline \multicolumn{3}{|l|}{ Middle scallop } \\
\hline Attachment (mm) & $19.3 \pm 4.1$ & NA \\
\hline Height (mm) & $13.8 \pm 2.9$ & $14 \pm 0.9$ \\
\hline \multicolumn{3}{|l|}{ Posterior scallop } \\
\hline Attachment (mm) & $13.6 \pm 3.3$ & NA \\
\hline Height (mm) & $11.0 \pm 2.3$ & $10 \pm 1.2$ \\
\hline \multicolumn{3}{|l|}{ Cleft chordae } \\
\hline Anterior (mm) & $14.5 \pm 3.2$ & $13 \pm 3.7$ \\
\hline Posterior (mm) & $14.9 \pm 3.2$ & $13 \pm 3.7$ \\
\hline \multicolumn{3}{|l|}{ Anterior commissural leaflet } \\
\hline Attachment (mm) & $7.7 \pm 2.1$ & $12 \pm 3.3$ \\
\hline Height (mm) & $8.7 \pm 2.4$ & $8 \pm 1$ \\
\hline Commissural chorda (mm) & $12.3 \pm 3.6$ & $13 \pm 0.2$ \\
\hline \multicolumn{3}{|l|}{ Posterior commissural leaflet } \\
\hline Attachment (mm) & $7.2 \pm 2.1$ & $17 \pm 0.8$ \\
\hline Height (mm) & $8.3 \pm 2.0$ & 8 \\
\hline Commissural chorda (mm) & $13.8 \pm 3.9$ & $15 \pm 0.05$ \\
\hline
\end{tabular}

NA, Not available.

distance between the plane and the papillary muscle tip, instead of an oblique distance from the tip to the anulus itself. They reported that D1 $(21 \pm 3 \mathrm{~mm})$ was shorter than D2 $(26 \pm 4 \mathrm{~mm})$. We did not find such a difference in this study. Although the posteromedial papillary muscle tends to be placed deeper in the left ventricle from the mitral annular plane than the anterolateral papillary muscle, ${ }^{19}$ there are variations. We and Carpentier and associates ${ }^{20}$ did not find a significant difference in the lengths of the chordae tendineae between those from the anterolateral papillary muscle and those from the posteromedial papillary muscle (Table I); the lengths of these chordae tendineae could be different if the depth of the papillary muscle in the left ventricle was significantly different. Other possible explanations for the discrepancy could be due to the different reference points of the mitral anulus to measure the distance. We measured the distances between the tip of the papillary muscle to the 2 corresponding points of the mitral anulus, which was not the same as those to the plane of the anulus. Also we measured the distance in vitro while applying gentle tension on the leaflets to straighten the chordae tendineae. This upward tension could minimize the difference, if any.

If annulo-papillary muscle continuity is to be restored with either ePTFE sutures or a mitral allograft in mitral valve replacement, preoperative or intraoperative determination of the distance between the tip of papillary muscle and the mitral anulus is crucial in each case, because of the anatomic variations of the papillary muscles such as position, number, shortening, or development. However, we think our anatomic findings can offer some guidance and the rule by which to determine the length for the procedure.

We gratefully acknowledge Yoichiro Kobashi, MD, for his preparation of the cardiac specimens and Joan Ivanov, MSc, for statistical consultation.

\section{REFERENCES}

1. Gams E, Schad H, Heimisch W, Hagl S, Mendler N, Sebening E. Preservation versus severance of the subvalvular apparatus in mitral valve replacement: an experimental study. Eur J Cardiothorac Surg 1990;4:250-6.

2. Yun KL, Rayhill SC, Niczyporuk MA, Fann JI, Zipkin RE, Derby $\mathrm{GC}$, et al. Mitral valve replacement in dilated canine hearts with chronic mitral regurgitation. Circulation 1991;84(Suppl):III11224.

3. Okita Y, Miki S, Kusuhara K, Ueda Y, Tahata T, Yamanaka K, et al. Analysis of left ventricular motion after mitral valve replacement with a technique of preservation of all chordae tendineae. J Thorac Cardiovasc Surg 1992;104:786-96.

4. David TE, Uden DE, Strauss HD. The importance of the mitral apparatus in left ventricular systolic function after mitral valve replacement. Circulation 1986;68:76-82.

5. Rozich JD, Carabello BA, Usher BW, Kratz JM, Bell AE, Zile MR. Mitral valve replacement with and without chordal preservation in patients with chronic mitral regurgitation. Circulation 1992;86:1718-26.

6. Miller DW Jr, Johnson DD, Ivey TD. Does preservation of the posterior chordae tendineae enhance survival during mitral valve replacement? Ann Thorac Surg 1979;28:22-7.

7. Spencer FC, Galloway AC, Colvin SB. A clinical evaluation of the hypothesis that rupture of the left ventricle following mitral valve replacement can be prevented by preservation of the chordae of the mural leaflet. Ann Surg 1985;202:673-80.

8. Acar C, Tolan M, Berrebi A, Gaer J, Gouezo R, Marchix T, et al. Homograft replacement of the mitral valve: graft selection, technique of implantation, and results in forty-three patients. J Thorac Cardiovasc Surg 1996;111:367-80.

9. David TE. Mitral valve replacement with preservation of chordae tendineae. Saudi Heart J 1990;1:32-6.

10. Okita Y, Miki S, Ueda Y, Tahata T, Sakai T, Matsuyama K. 
Replacement of chordae tendineae using expanded polytetrafluoroethylene (ePTFE) sutures during mitral valve replacement in patients with severe mitral stenosis. J Card Surg 1993;8:567-78.

11. Lam JH, Raganathan N, Wigle ED, Silver MD. Morphology of the human mitral valve. I. Chordae tendineae: a new classification. Circulation 1970;41:449-58.

12. Okita Y, Miki S, Ueda Y, Tahata T, Sakai T, Matsuyama K. Mitral valve replacement with maintenance of mitral annulopapillary muscle continuity in patients with mitral stenosis. J Thorac Cardiovasc Surg 1994;108:42-51.

13. Ramsheyi S-A, Pargaonkar S, Lassau J-P, Acar C. Morphologic classification of the mitral papillary muscles. J Heart Valve Dis 1996;5:472-6.

14. Frater RWM. Anatomical rules for the plastic repair of a diseased mitral valve. Thorax 1964;19:458-64.

15. Komeda M, DeAndam A Jr, Glasson JR, Bolger AF, Nikolic SD, et al. Improving methods of chordal-sparing mitral valve replace- ment. Part II. Optimal tension for chordal resuspension. J Heart Valve Dis 1996;5:477-83.

16. Gash AK, Carabello BA, Cepin D, Spann JF. Left ventricular ejection performance and systolic muscle function in patients with mitral stenosis. Circulation 1983;67:148-5.

17. Liu CP, Ting CT, Yang TM, Chen JW, Chang MS, Maughan WL, et al. Reduced left ventricular compliance in human mitral stenosis: role of reversible internal constraint. Circulation 1992;85:1447-56.

18. Komeda M, Glasson JR, Bolger AF, Daughters GT II, Ingels NB Jr, Miller DG. Papillary muscle-left ventricular wall "complex." J Thorac Cardiovasc Surg 1997;113:292-301.

19. Rusted IE, Scheifley CH, Edwards JE. Studies of the mitral valve. I. Anatomic features of the normal mitral valve and associated structures. Circulation 1952;6:825-31.

20. Carpentier A, Guerinon J, Deloche A, Fabiani JN, Relland J. Pathology of the mitral valve. In: Kalmanson D, editor. The mitral valve. London: Edward Arnold; 1976. p. 65-77.

\section{Bound volumes available to subscribers}

Bound volumes of The Journal of Thoracic and Cardiovascular Surgery are available to subscribers (only) for the 1999 issues from the Publisher, at a cost of $\$ 134.00$ for domestic, $\$ 165.85$ for Canadian, and $\$ 155.00$ for international subscribers for Vol 117 (January-June) and Vol 118 (July-December). Shipping charges are included. Each bound volume contains a subject and author index and all advertising is removed. Copies are shipped within 60 days after publication of the last issue of the volume. The binding is durable buckram with the Journal name, volume number, and year stamped in gold on the spine. Payment must accompany all orders. Contact Mosby, Inc, Subscription Services, 11830 Westline Industrial Drive, St Louis, MO 63146-3318, USA; phone 800-453-4351 or 314-453-4351.

Subscriptions must be in force to qualify. Bound volumes are not available in place of a regular Journal subscription. 